\title{
OPTICAL PROBE FOR LOCAL VOID FRACTION AND INTERFACE VELOCITY MEASUREMENTS
}

\author{
N. Abuaf, 0.C. Jones, Jr., and G.A. Zimmer
}

EXPERIMENTAL MODELING GROUP

DATE PUBLISHED - MARCH 1978

DEPARTMENT OF NUCLEAR ENERGY BROOKHAVEN NATIONAL LABORATORY UPTON, NEW YORK 11973 


\section{DISCLAIMER}

This report was prepared as an account of work sponsored by an agency of the United States Government. Neither the United States Government nor any agency Thereof, nor any of their employees, makes any warranty, express or implied, or assumes any legal liability or responsibility for the accuracy, completeness, or usefulness of any information, apparatus, product, or process disclosed, or represents that its use would not infringe privately owned rights. Reference herein to any specific commercial product, process, or service by trade name, trademark, manufacturer, or otherwise does not necessarily constitute or imply its endorsement, recommendation, or favoring by the United States Government or any agency thereof. The views and opinions of authors expressed herein do not necessarily state or reflect those of the United States Government or any agency thereof. 


\section{DISCLAIMER}

Portions of this document may be illegible in electronic image products. Images are produced from the best available original document. 


\title{
OPTICAL PROBE FOR LOCAL VOID FRACTION AND INTERFACE VELOCITY MEASUREMENTS
}

\author{
N. Abuaf, 0.C. Jones, Jr., and G.A. Zimmer
}

Brookhaven National Laboratory

Department of Nuclear Energy

Experimental Modeling Group

Upton, New York 11973

\section{Manuscript Completed - November 1977 \\ Date Published - March 1978}

Prepared for the U.S. Nuclear Regulatory Commission

Office of Nuclear Regulatory Research

Contract No. EY-76-C-02-0016 

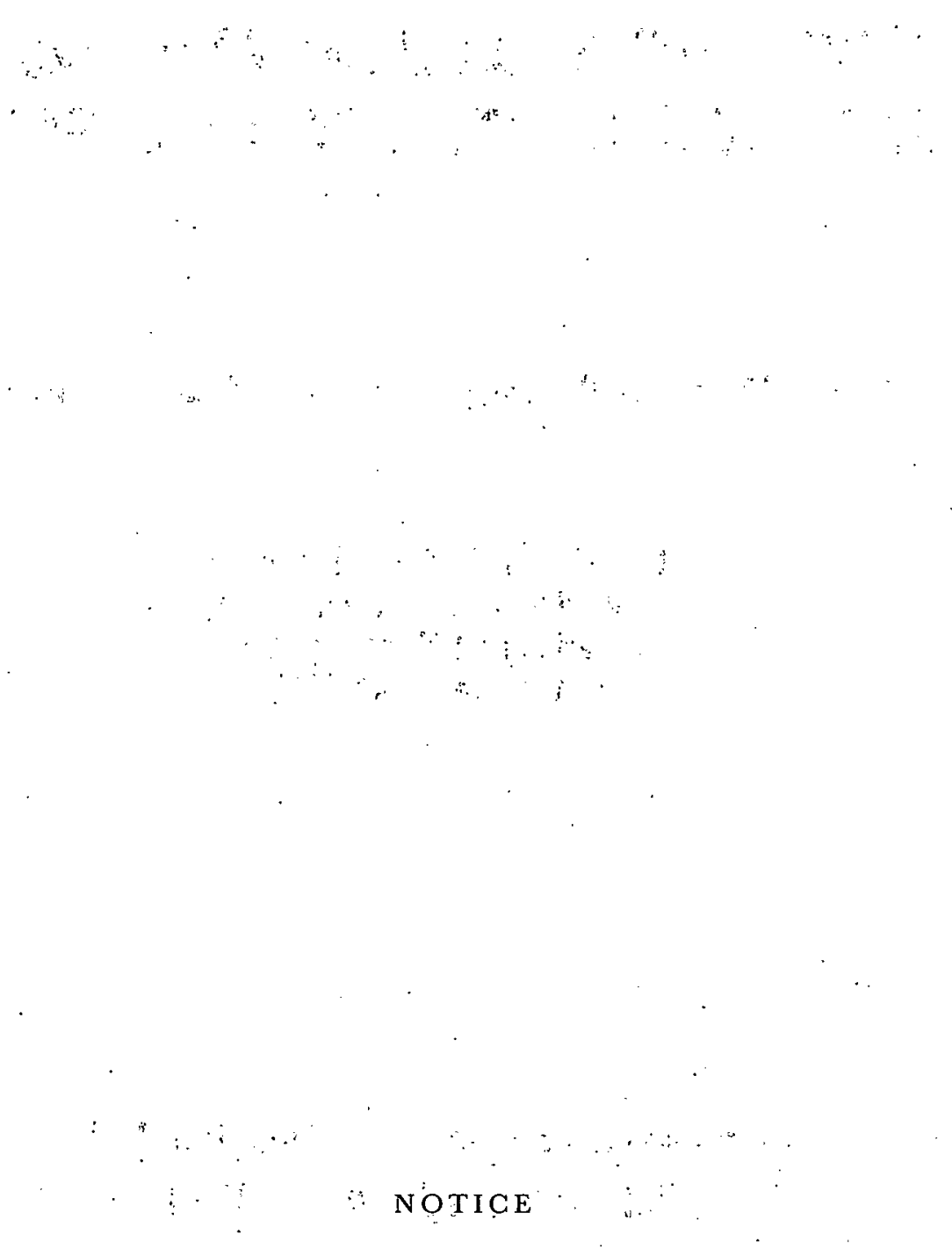

This report was prepared as an account of work sponsored by the United States Government. Neither the United States nur the United States Nuclear Regulatory Commission, nor any of their employees, nor any of their contractors, subcontractors, or their employees, makes any warranty, express or implied, or assumes any legal liability or responsibility for the accuracy, completeness or usefulness of any informa-

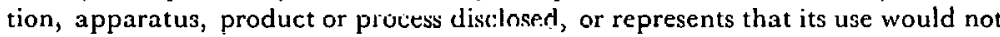
infringe privately owned rights.

Printed in the United States of America Available from

National Technical Information Service

U.S. Department of Commerce

5285 Port Royal: Road

Springfield, VA 22161

Price: Printed Copy Microfiche $\$ 3.00$

March 1978 


\section{ACKNOWLEDGEMENT}

The authors are indebted to Thomas P. Feierabend and Anita L. Swoboda for their invaluable help and fruitful discussions.

This research was sponsored by the U.S. Nuclear Regulatory Commission. 
TABLE OF . CONTENTS

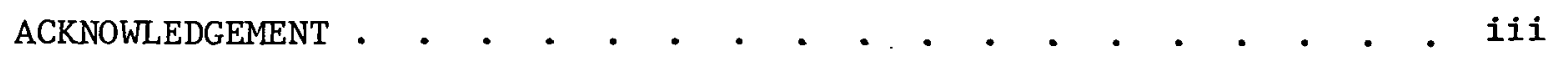

LIST OF FIGURES : • • • • • • • • • • • • • • • • • • • . iv

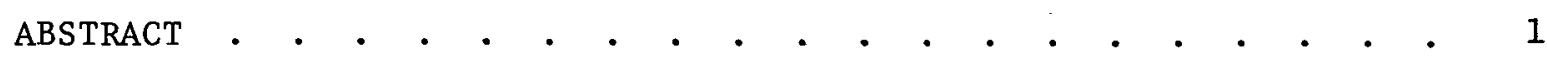

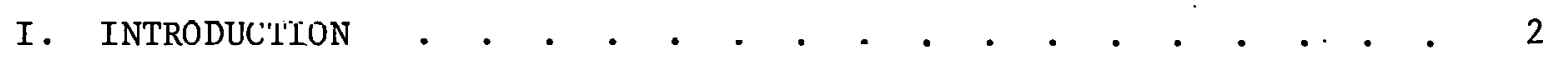

II. OPTICAL PROBES •

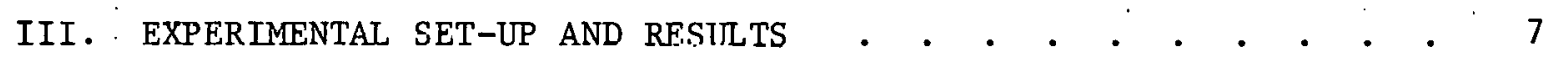

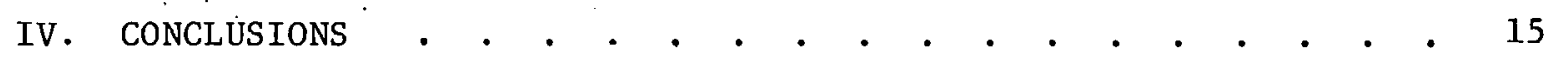

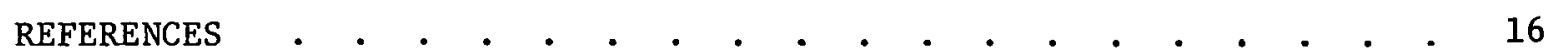

LIST OF FIGURES

Figure

1. Operation Principle of Optical Probes......... 5

2. Schematic Representation of the Optical Probe.. . . . 7

3. Production Techniques ............. 8

4. Schematic of Experimental Set-Up for Probe Calibration. 10

5. Typical Oscillograms of the Output. . . . . . . . 12

6. Bubble Penetration Time as a Function of Bubble . . . 12 Velocity.

7. Plot of Probe Signal Amplitude at a given Bubble. . . . 14 Velocity, I, Divide by the Steady Probe Output in Air, $I_{0}$, as a Function of Bubble Velocity.

8. Sketch of $45^{\circ}$ Probe Tip with Water Film. . . . . . 14 
ABSTRACT

In view of the importance of obtaining insteady local void fraction and interface velocities in liquid-vapor two-phase flows, an optical probe with a. controlied tip geometry was developed and is described. In order to. minimize the disturbances caused to the flow field by the presence of the probe, its dimensions have been miniaturized. The electronic and hydrodynamic response of the probe were investigated experimentally. The probe was found to be sensitive to both the interface velocities and the phase present at the probe tip. A possible explanation for the behavior of the probe is presented. Within the velocity range checked and with proper calibration, the optical probe developed can be used to determine both local void fractions and interface velocities. 


\section{INTRODUCTION}

Two-phase flows consisting of the simultaneous flow of liquid-vapor or liquid-gas are encountered quite frequently in power generation systems, heat transfer equipment; chemical reactors and other industrial hardware. Such flows are also familiar phenomena in the cooling systems of boiling or pressurized water reactors.

In liquid-vapor flows, several flow regimes are encountered where the vapor phase may occur in various patterns from small bubblcs to large slugs or in continuous columns with or without 1:iquid films or droplets. The bubble sizes and their distributions in these regimes vary with the 11quid velocities, gas flow rates, flow geometries and local conditions. To obtain a detailed knowledge of the flow regimes and the local thermal and flow characteristics is very important in developing predictive tools for calculating local heat transfer rates and temperatures, crucial, for instance, in some reactor studies. In addition, some theoretical modeling of two-phase flow studies under equilibrium and non-equilibrium conditions (flashing flows) are based on very specific local thermal and hydraulic conditions. An experimental verification of such analytical descriptions thus require a very fine and detailed determination of the relevant local parameters, i.e., local void fractions, phase velocities, and thermodynamic properties, among others.

Two-phase flow instrumentation for void fraction measurement techniques are classified as global or local. Global methods provide measurements giving line, area or volume averages, and local instantaneous methods provide measurements at specific locations. The latter type requires the insertion at the point of interest of a probe which detects changes in physical properties inherent in the two phases, i.e., electrical resistivity, thermo physical properties, or index of refraction. The local probes may be on-off devices yielding time 
average phase residence times. In steady flows, the time-ayeraged void fraction information they prơvide is defined as:[1].]

$$
\alpha=\frac{\mathrm{T}_{\alpha}}{\mathrm{T}}
$$

where $T$ is the total measurement time and $T_{\alpha}$ is the time fraction of $T$ during which the vapor or gas phase was present at the specific location. To. determine interface velocities, two consecutive probes are situated at a known distance from each other in the flow direction. By using a time-of-flight technique or cross-correlation of the two signals, for instance, the necessary time periods for the interface to travel from one probe to the other are determined. With this information, the interface velocity can be calculated which in turn, with the knowledge of the evaporative mass flux provides the velocities of the two phases.

Considering the response of the local probes to the passage of the interfaces, three major areas can be defined as.important:

1. The electronic response of the system should be compatible with the bubble sizes, the interface velocities and the physical dimensions of the probe tip.

2. The hydrodynamic characteristics at the probe tip during the passage of the interface should be understood in order to analyze the signals obtained.

3. The influence of the presence of the probe on the flow and the bubble dynamics should be clarified in order to minimize the disturbance caused on the local flow properties.

In this paper, a local optical probe with a controlled tip geometry. is described and its response to the passage of interfaces is investigated. 


\section{OPTICAL PROBES.}

The operation principle of the optical probe has been described by Miller and Mitchie [2,3], and Danel and Delhaye [6] among others and summarized by Delhaye and Jones [12], is quite simple based on Snell's law (Fig. 12

$n \sin \hat{i}=n_{0} \sin i_{0}$

For a glass probe tip with an index of refraction of $n_{0}=1.62$, total probe tip angle of $90^{\circ}$ and coherent light rays parallel to the axis, $i_{0}=45^{\circ}$, the 1ight rays will be reflected back if $\mathrm{n}<1,15$, and will be refracted if $\mathrm{n}>1.15$, where $\mathrm{n}$ is the index of refraction of the media surrounding the probe tip. A probe operating on this principle will enable the detection of the gas and vapor or liquid phases present at the probe tip if $\mathrm{n}_{\mathrm{V}}<1.15^{\circ}<\mathrm{n}_{\mathrm{L}}$. This range includes the detection of freon and freon vapor, water and steam, and of water and air combinations.

Three optical probe configurations and geometries have been reported and used in the literature:

1. The glass rod probe of Miller and Mitchie [2, 3], where the tip was terminated as a cone with a $90^{\circ}$ apex angle. This probe was used in the study of a submerged impinging gas jet '[4].

2. The fiber bundle probe of Hinata [5] terminated as a glass rod and used in mercury-air two-phase flow in a vertical pipe.

3. The U-shaped fiber probe of Danel and Delhaye [6] which was successfully used in various two-phase flow studies $[1,7,8,9]$.

The signal analysis and the methods for obtaining the required local information on void fraction and interface velocities include triggering techniques and pulse height analysiss and are clearly described in the above mentioned references $[1,2,5]$. 

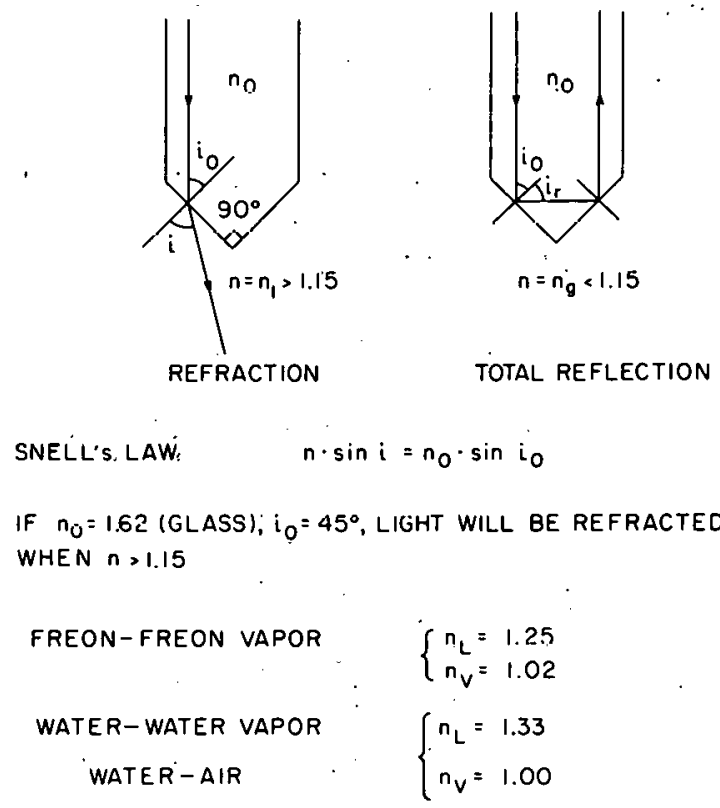

Figure 1. Operation principle of optical probes. 
Two observations common to all the probes mentioned above were:

1. Instead of obtaining a clear on-off signal during the passage of an interface, the static levels of the signals and the fluctuations caused by the passage of the bubbles varied with the void fraction. Thus a double triggering system was proposed where the threshold levels were determined from a calibration test against a $\gamma$-ray absorption technique [1].

2. The penetration time of the probe into a bubble or gas phase was longer than the time 1 to tok for the probe to be completely immersed in the liquid. This effect was observed to vary with bubble size and flow velocity. These observations were attributed to electronic or hydrodynamic response problems, but no basic investigation of the phenomena was undertaken. With these considerations a simpler geometry for the optical probe was proposed [10] and development of the production techniques and study of the electronic and hydrodynamic response of the probe was undertaken. It is the purpose of this paper to describe the results of this effort. In particular, it will be shown that there is a clear and repeatable sensitivity to interface velocity heretofore unreported and that this sensitivity is consistant from probe-to-probe of like geometries. 


\section{EXPERIMENTAL SET-UP AND RESULTS}

A schematic of the probe as developed is depicted in Fig. 2, with the light source and amplifier circuit diagram. The construction procedure is documented in Fig. 3. Two $125 \mu \mathrm{m}$ fibers were inserted into a $500 \mu \mathrm{m}$ OD stainless steel tube. The two fibers were fused together at one end by means of a minitorch, forming a spherical bead. This fused end of the fibers was then pulled into the tube and epoxied in place. The fibers were separated at the opposite end and encased into two pieces of stainless steel tubing (250 $\mu \mathrm{m}$ O.D.). The ends of the fibers and the bifurcation were then epoxied

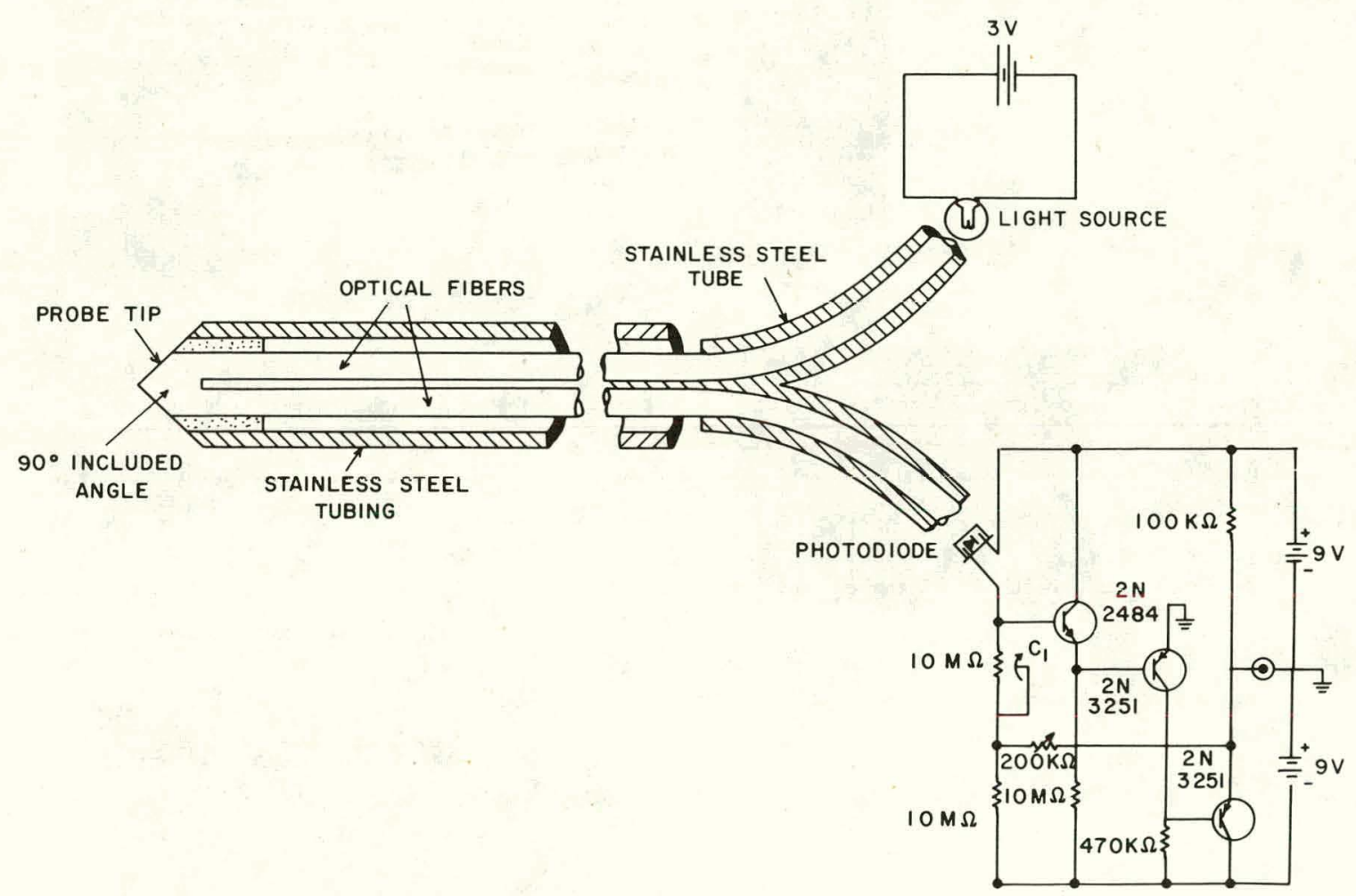

Figure 2. Schematic representation of the optical probe. 


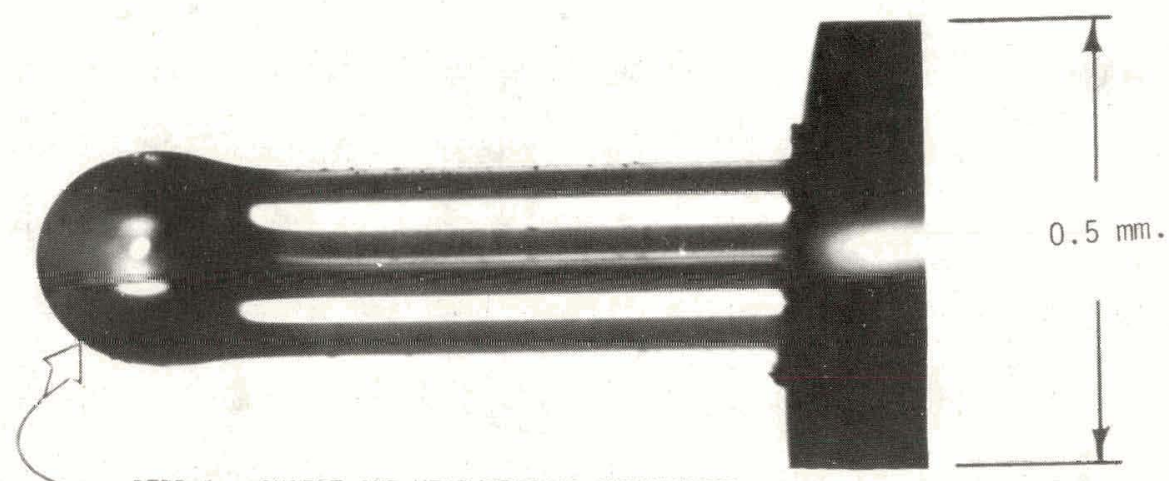

STEP 1: INSERT AND WELD OPTICAL WAVEGUIDES

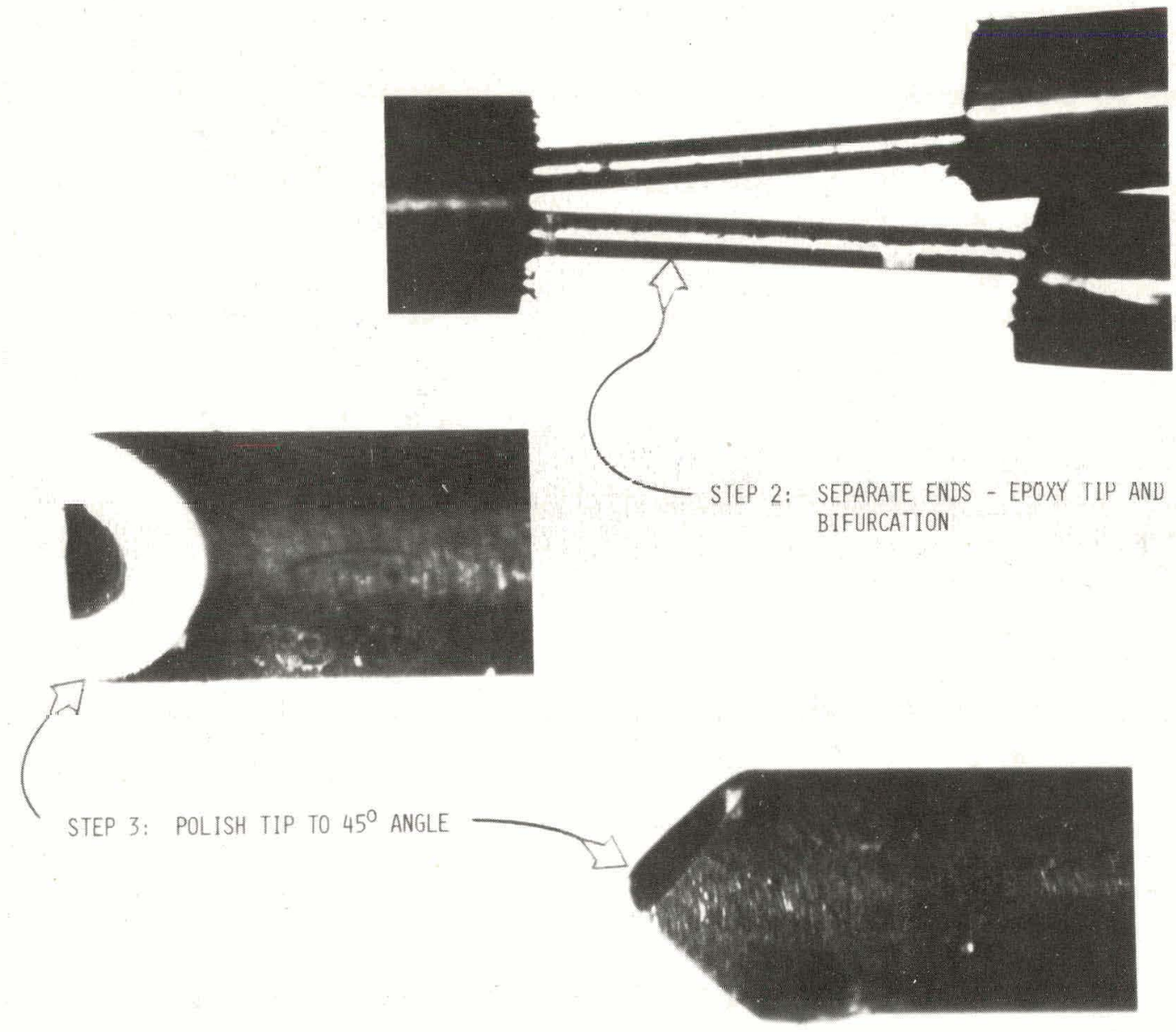

Figure 3. Production techniques. 
for strength. The tip of the probe containing the fused end of the fibers was ground and polished at $45^{\circ}$ angle to the axes of the fibers, thus forming an included angle of $90^{\circ}$ at the finished probe tip. After grinding and polishing the free ends of the two fibers flat, one of them was placed in front of an incandescent light source $(3 \mathrm{v})$, and the other in front of a Hewlett Packard PIN photodiode (5082-4024). An amplifier with a design rise time of $20 \mu \mathrm{sec}$ [11] was used to enhance the output before going into the readout device (Fig. 2). The electronic response of the system was checked by means of a light emitting diode (LED) placed in front of the probe tip. The LED output was modulated by using a signal generator. Light pulses of different frequencies and durations were emitted, simulating the passage of bubbles. The rise time of the output was thus verified to be $20 \mu \mathrm{sec}$ as specified and no reduction in signal amplitude was recorded. The hydrodynamic response of the probe to the passage of an interface or bubble was investigated by means of an experimental set-up presented in Fig. 4. It consisted of a glass tube $(0.64 \mathrm{~cm}$ I.D. and $83 \mathrm{~cm}$ long, attached at one end to a reservoir open to the atmosphere and at the other end, through a ball valve to a pressurized reservoir. Air bubbles could be injected at the base of the glass tube by mans of a needle valve. Each air bubble, filling an entire tube cross section, travels along the tube, hitting the optical probe head on. Such a constricted configuration eliminates the possibility of the bubbles avoiding the probe at low approach velocities as was observed in the case of small bubbles and large pipe diameters [13, 14]. In order to obtain bubble velocities higher than the normal rise velocity in the tube, the water in the upstream reservoir was pressurized by means of bottled air. Opening the ba.11 valve released the pressurized water, thus accelerating the liquid and the air bubble at the same time. 


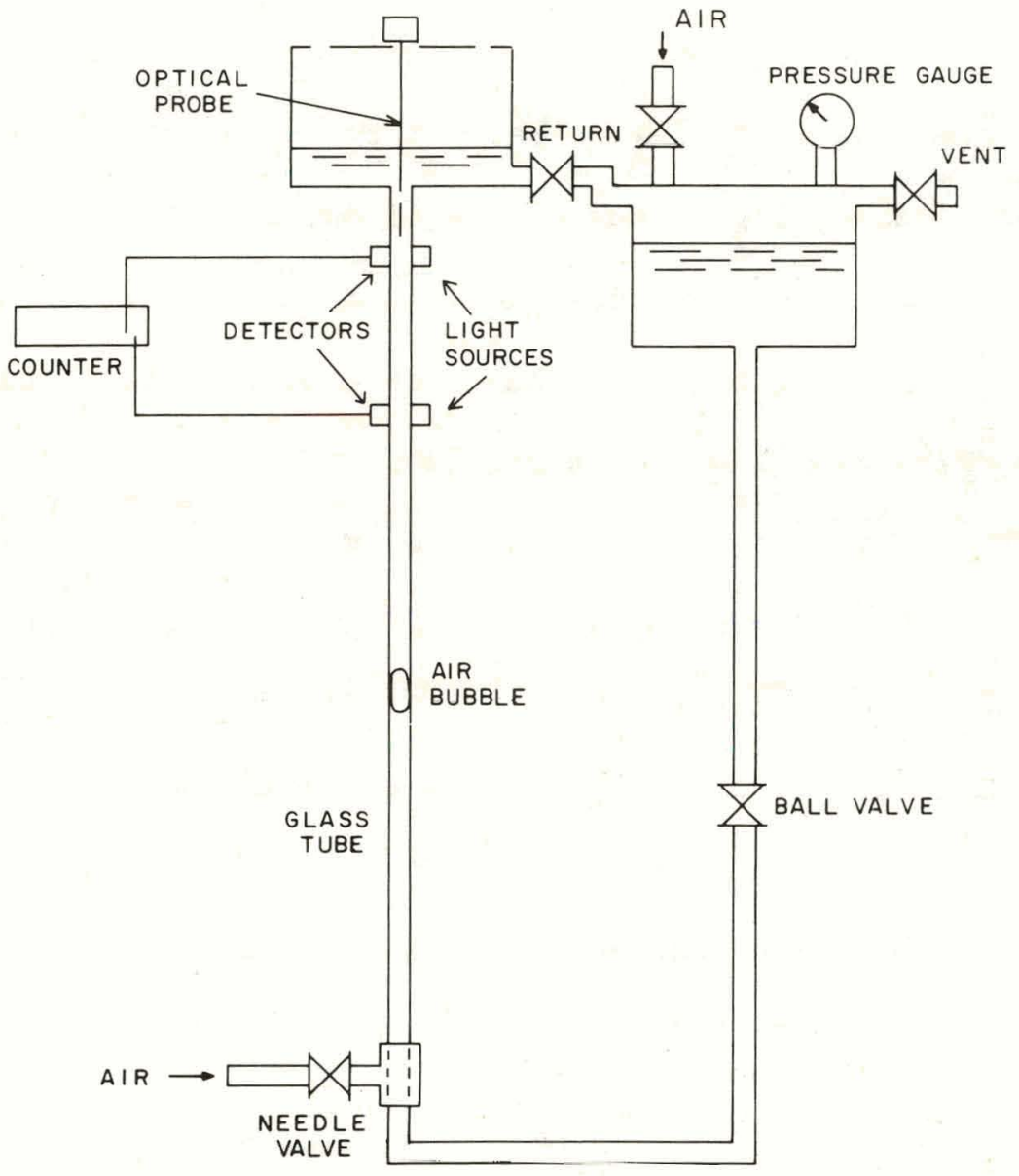

Figure 4. Schematic of experimental set-up for probe calibration. 
The velocity of the bubble along the glass tube was measured before it reached the probe tip by means of two diametrically opposed light sources and detectors. The latter through light attenuation sensed the passage of the first interface, thus starting and stopping a counter (HP 5325 B). Given the distance between the detectors, an average bubble velocity was thus calculated with 1 percent accuracy. Bubble velocities ranging from $0,7 \mathrm{~cm} / \mathrm{sec}$ to $280 \mathrm{~cm} / \mathrm{sec}$ were obtained with this experimental set-up. The output of each detector also gave information about the length of the bubble once the average velocity was calculated.

After passing through the second detection station, the bubble hit the optical probe. Typical oscillograms of the probe output during the passage of the bubble are presented in Fig. 5. Here the probe output in mv is shown as a function of time for two cases where the bubble velocities were $19 \mathrm{~cm} / \mathrm{sec}$ and $74 \mathrm{~cm} / \mathrm{sec}$, respectively. One observation was that the probe output when the tip was immersed in water was always zero without any artificial bias. As the bubble hit the probe the output was seen to increase, and after an overshoot leveled off to a certain steady value. At the end of the passage of the bubble, the signal dropped to its original water level of zero. The bubble penetration time was clearly observed to be larger than the time it takes the probe tip to be immersed in water. The most important observation here was that the signal amplitude decreased with the increasing bubble velocity, although both bubbles had almost the same length, (void fraction). Figure 6 presents the variation of the bubble penetration time as a function of the average bubble velocity. The bubble penetration time is defined as the time period between the arrival of the bubble at the tip (first increase in the signal) and the moment when the steady signal value is reached for the first time. At bubble velocities $U_{B}>40 \mathrm{~cm} / \mathrm{sec}$, the penetration times follow a const $/ U_{B}$ variation 


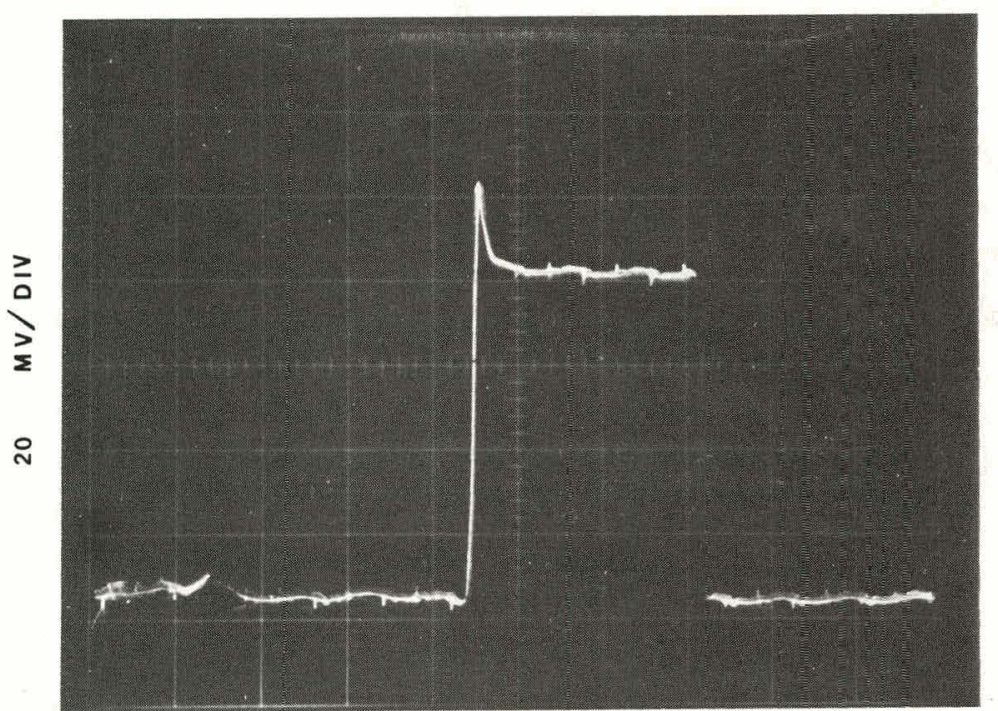

$20 \mathrm{MS} / \mathrm{DIV}$

I

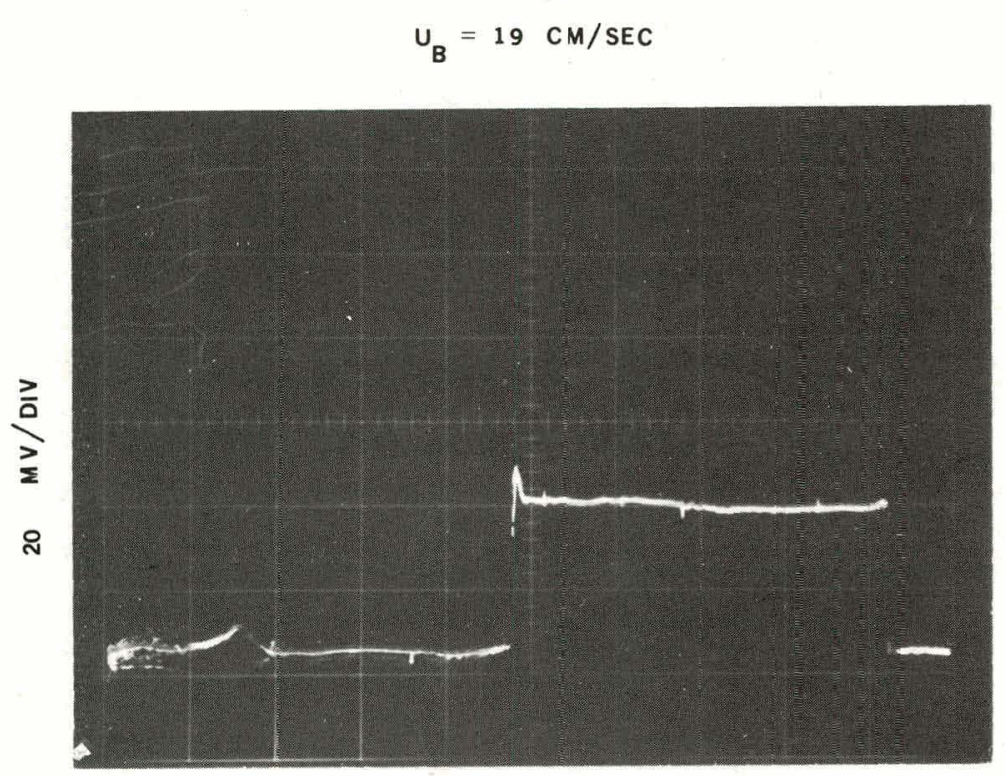

$5 \mathrm{MS} / \mathrm{DIV}$

$U_{B}=74 \mathrm{~cm} / \mathrm{SEC}$

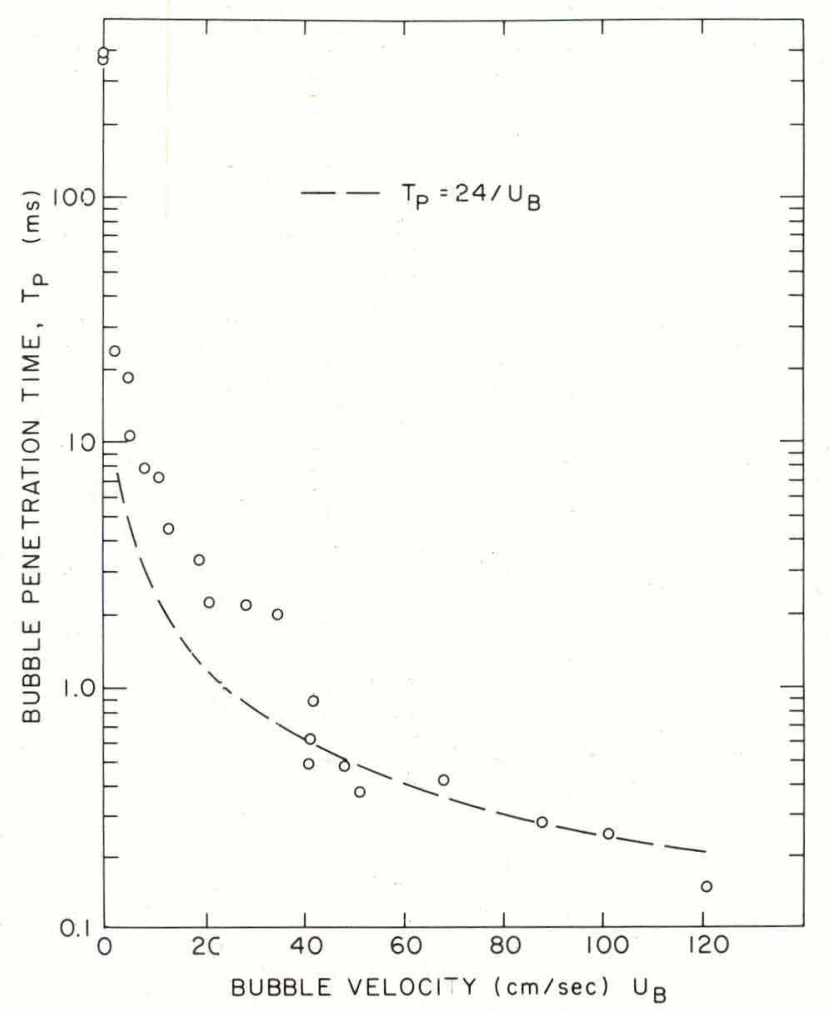

Figure 6. Eubble penetration time as a function of bubble velocity.

Figure 5. Typical oscillograms of the sutput. 
depicting dominant inertia effects. The penetration times that are predicted from a characteristic physical length of the probe tip are 35 percent shorter than those observed experimentally. At low bubble velocities, $\mathrm{U}_{\mathrm{B}}<40 \mathrm{~cm} / \mathrm{sec}$, the penetration times are longer than the const./ $U_{B}$ predictions suggesting additional surface tension effects become important."

Figure 7 depicts the variation of the ratio of the probe signal amplitude at various bubble velocities to the signal amplitude in stagnant air, the latter one, $I_{0}$, being determined under steady conditions with the tip of the probe dry. Results obtained with two different probes are presented in Fig. 7 as a function of bubble velocity. Although the two probes had a steady air signal amplitude of $125 \mathrm{mv}$ and $600 \mathrm{mv}$ respectively, the ratio I/I; seems to follow the same consistent pattern.

A similar observation was noted but not pursued by Miller and Mitchie [3], "With smaller bubbles and higher velocities..... The probe signal generated under these conditions..... never reached maximum amplitude."

An important conclusion that can be drawn from Fig. 7, is that the developed optical probe is able to measure the local interface velocity, as well as the local void fraction, after proper calibration within the velocity range observed. From Fig. 7, one observes that when the probe tip is completely dry in air, the maximum signal output is attained. It was thought that these results were due to a variable, velocity sensitive liquid film on the probe tip although the results seemed opposed to normal expectations considering shear-driven stable films. If a liquid film exists on the probe tip similar to that shown in Fig. 8, there is some thickness $\delta$ beyond which the probe will appear to be totally immersed in liquid (ideally complete refraction of the light). Using Snell's Law, one obtains for coherent light rays, an angle $\beta=54.5^{\circ}$. Assuming a linear variation of the film thickness along the probe tip, a 


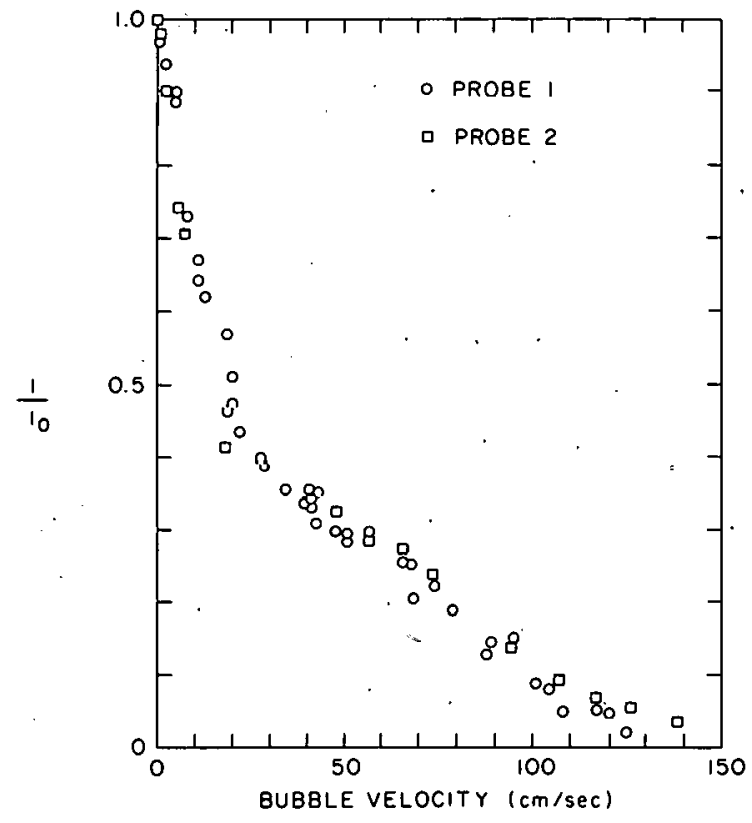

Figure 7. Plot of probe signal amplitude at a given bubble velocity, I, divided by the steady probe output in air, $I_{0}$ as a function of bubble velocity.

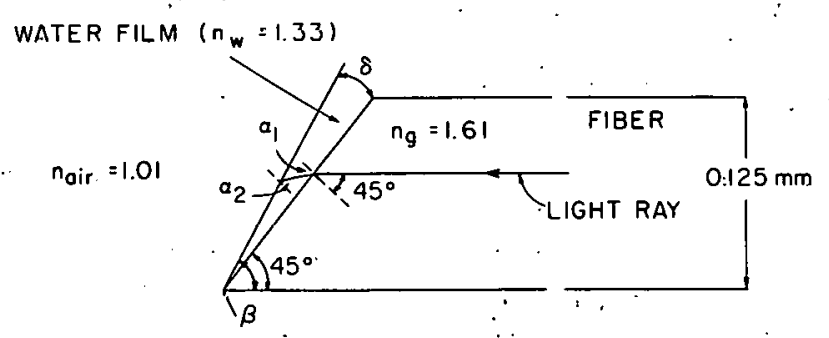

Figure 8. Sketch of $45^{\circ}$ probe tip with water film. 
water film thickness of $29.2 \mu \mathrm{m}$ and above, at the tip of a $125 \mu \mathrm{m}$ fiber, would cause the probe to behave as if it were still in water. Since the light supplied to the probe was not coherent but, instead, filied the acceptance angle for the optical waveguide, a water film left at the probe tip during the passage of the bubble and increasing in thickness with the bubble velocity, would cause increasingly larger amounts of light to be refracted out of the probe. Such behavior would provide an explanation for the variation observed in Fig. 7.

IV. CONCLUSIONS

1. An optical probe technique capable of measuring local interface velocity, as well as void fraction was developed.

2. The new design, since it is encased in a stainless steel tube, is sufficiently strong to stand more difficult conditions.

3. A potential physical explanation for the probe behavior has been identified. 


\section{REFERENCES}

1. J. P. Galaup, Thesis presented at the Universite Scientifique et Medicale de Grenoble et I'Institut National Polytechnique de Grenoble, 1975.

2. N. Miller and R. "E. Mitchie, in Two-Phase Flow Instrumentation, ASME, 1969.

3. N. Miller and R. E. Mitchie, J. Brit. Nucl. Energy Soc., 9, 94, 1970.

4. R. Bell, B, E. Royce and J. G. Collier, J, Brit. Nucl. Energy Soc., $11,183,1972$.

5. S. Hinata, Bulletin of the JSME, 15, 88, 1228, 1972.

6. F. Dane1 and J. M. Delhaye, Mesures, Aug-Sept., 99, 1971.

7. J. P. Galaup and R. Charlot, Mesure du Taux de Vide Local a I'Aide d'une Sonde Optique, Note T. T. No. 458, C.E.N.G., 1974.

8. J. P. Galaup and J. M. Delhaye, La Houille Blanche, 1, 17, 1976.

9. J. M. Delhaye and J. P. Galaup, Measurement of Local Void Fraction in Freon 12 with a $0.1 \mathrm{~mm}$ Optical Fiber Probe, European Two-Phase Flow Meeting, Harwe11, June 1974.

10. 0. C. Jones, Jr:, BNL Light Water Reactor Thermohydraulic Development Program Instrumentation Tasks, BNL-NUREG-22588, March 1977.

11. Hewlett Packard Application Note 915.

12. J. M. Delhaye and O. C. Jones, Jr., "A Summary of Experimental Methods for Statistical and Transient Analysis of Two-Phase Gas-Liquid Flow," ANL-76-75, 1976.

13. Delhaye, J. M., Thesis presented at the Faculte des Sciences de 1 'Universite de Grenoble, 1970.

14. Nassos, G. P., "Development of an Electrical Resistivity Probe for Void Fraction Measurements in Air-Water Flow, ANL-6738, June 1963. 


\section{Distribution List}

BNL RSP Division Heads

BNL RSP Group Leaders

BNL RSE Modeling Group

D. Basdekas, NRC

S : Fabic, , NRC

Y. Y. Hsu, NRC

S. Lane, BNL

M. Silberberg, NRC

R. W. Wright, NRC

N. Zuber, NRC

NRC Distribution List $\#_{2}$ 


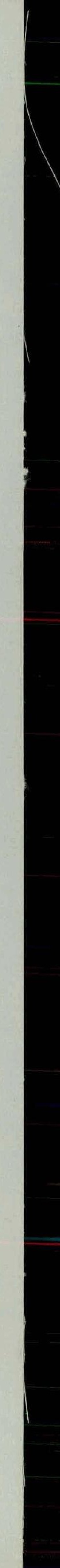

